
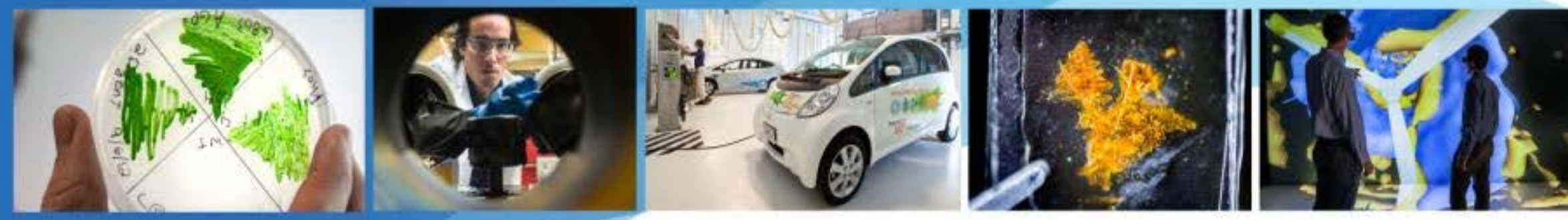

\section{Seasonal Trends of Soiling on Photovoltaic Systems}

Leonardo Michelia,b, Daniel Rutha, Matthew Muller ${ }^{\mathrm{a}}$

a) National Renewable Energy Laboratory, Golden, CO, USA.

b) Colorado School of Mines, Golden, CO, USA.

June $28^{\text {th }}, 2017-44^{\text {th }}$ IEEE Photovoltaic Specialists Conference 


\title{
Introduction
}

Soiling stations: common way to quantify soiling.

$\rightarrow$ Consist of two reference cells (or modules).

$$
\text { daily Soiling Ratio }=\frac{I_{S C_{\_} \text {Soiled }}}{I_{S C_{-} \text {Control }}}
$$

(Avg. of 12PM and 1PM data, only POA irradiance $>500 \mathrm{~W} / \mathrm{m}^{2}$ )

\author{
daily SRatio = 1 at clean conditions, \\ daily SRatio $<1$ in soiling conditions.
}




\section{Introduction}

\section{Particulate matter (i.e. concentration of particles suspended in air) has the best correlation with Sratio for long time periods (> 6 months) in the USA [1].}

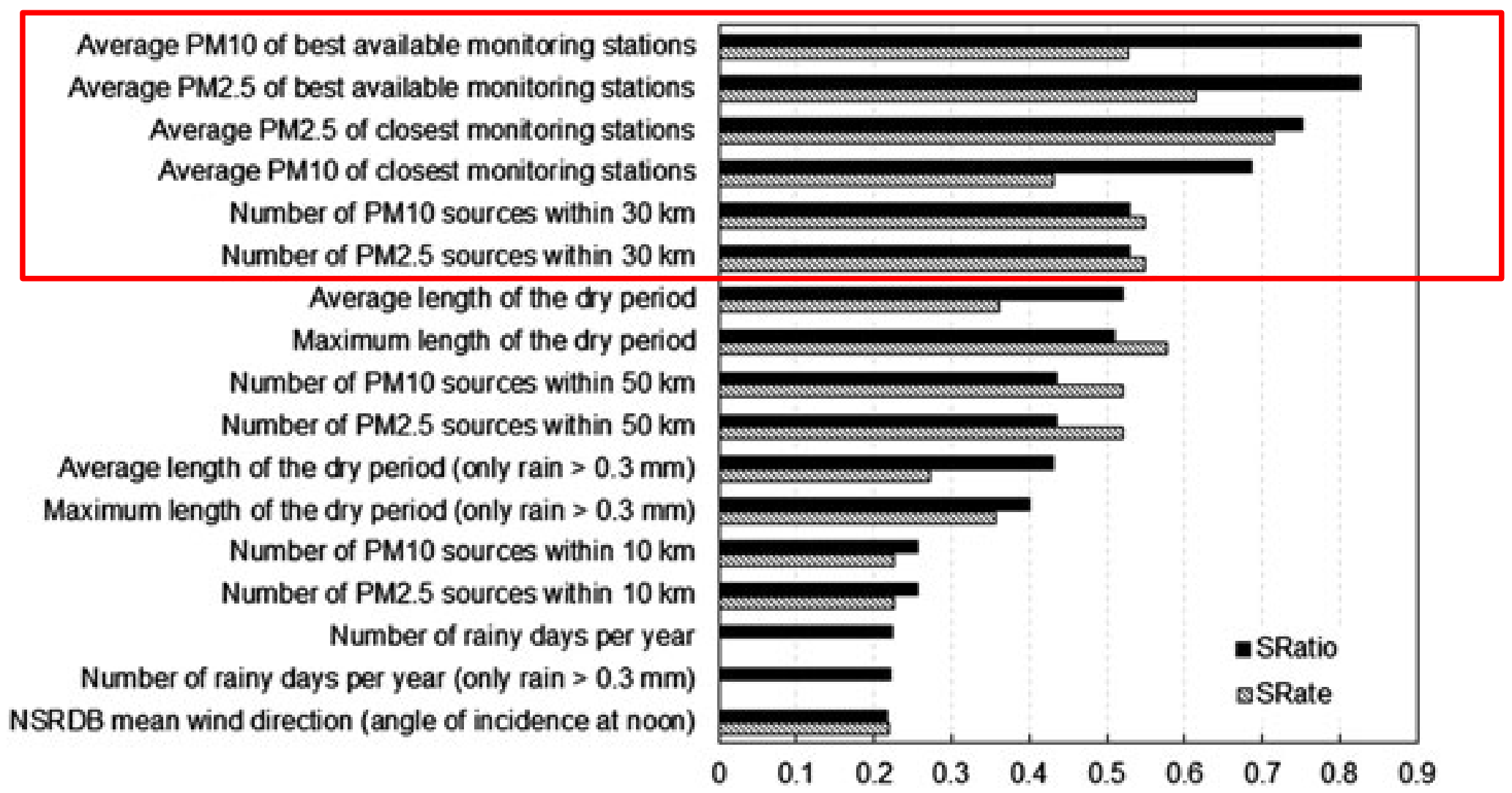

Parameters with the highest coefficient of determination when related to soiling ratios and soiling rates.

[1] L. Micheli and M. Muller, Prog. Photovoltaics Res. Appl. 25, 291 (2017). 


\section{Introduction: Motivation}

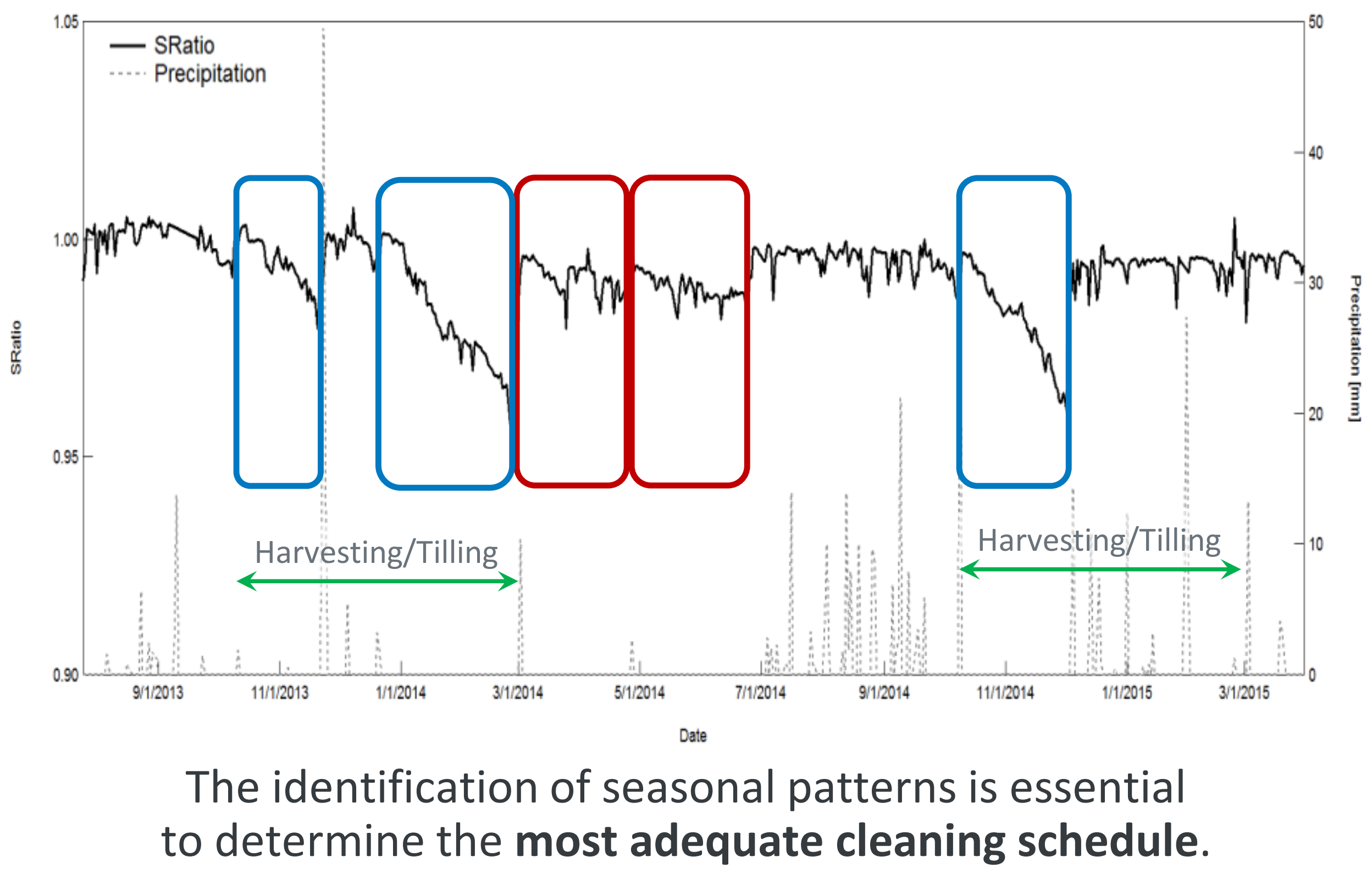




\section{Introduction: Aim}

- Providing an instrument to quantify the seasonal soiling.

- Investigating, with a systematic approach, the seasonal soiling occurring at 15 different sites over a 12-month period.

- Analyzing the causes of seasonal soiling. 


\section{Introduction: Definition of seasonal soiling}

Colwell [2], using the term "contingency," defined seasonality as the degree to which time and states statistically dependent on each other.

Our aim is identifying how much soiling can vary in one year ("variability") and which factors are driving these changes. 


\section{Introduction: Classification of seasonality}

"Seasonality Index" (SI): parameter introduced in 1981 to describe the degree of variability in monthly rainfall through one year [3].

\begin{tabular}{|c|c|}
\hline SI & Class \\
\hline$<0.2$ & Very equable \\
\hline$\geq 0.2$ and $<0.4$ & Equable, but with a definite wetter season \\
\hline$\geq 0.4$ and $<0.6$ & Rather seasonal with a short drier season \\
\hline$\geq 0.6$ and $<0.8$ & Seasonal \\
\hline$\geq 0.8$ and $<1.0$ & Markedly seasonal, with a longer drier season \\
\hline$\geq \mathbf{1 . 0}$ and $<\mathbf{1 . 2}$ & Most rain in 3 months or less \\
\hline$\geq 1.2$ & Extreme, almost all rain in 1-2 months \\
\hline
\end{tabular}


"Seasonality Index" has been adapted to describe the variability of soiling across a 12-month period and renamed as "Soiling Variability Index" (SVI).

$$
S V I(\text { site })=\frac{\sum_{m=1}^{12}\left|S_{m}(m)-\left(S_{m_{-} \text {sum }} / 12\right)\right|}{S_{m_{-} \text {sum }}}
$$

With the monthly soiling metric $\left(\mathrm{S}_{\mathrm{m}}\right)$ being:

$$
S_{m}(m)=\sum_{d=1}^{n_{d}}(1-\text { dailySRatio }(d))
$$

$S_{m}$ is 0 if no soiling occurred; otherwise, it is always greater than 0. 


\section{As for the Seasonality Index,}

- the Soiling Variability Index varies

- from 0 (no variability: same soiling occurring any month)

o to 1.83 (max variability: all soiling accumulated in 1month)

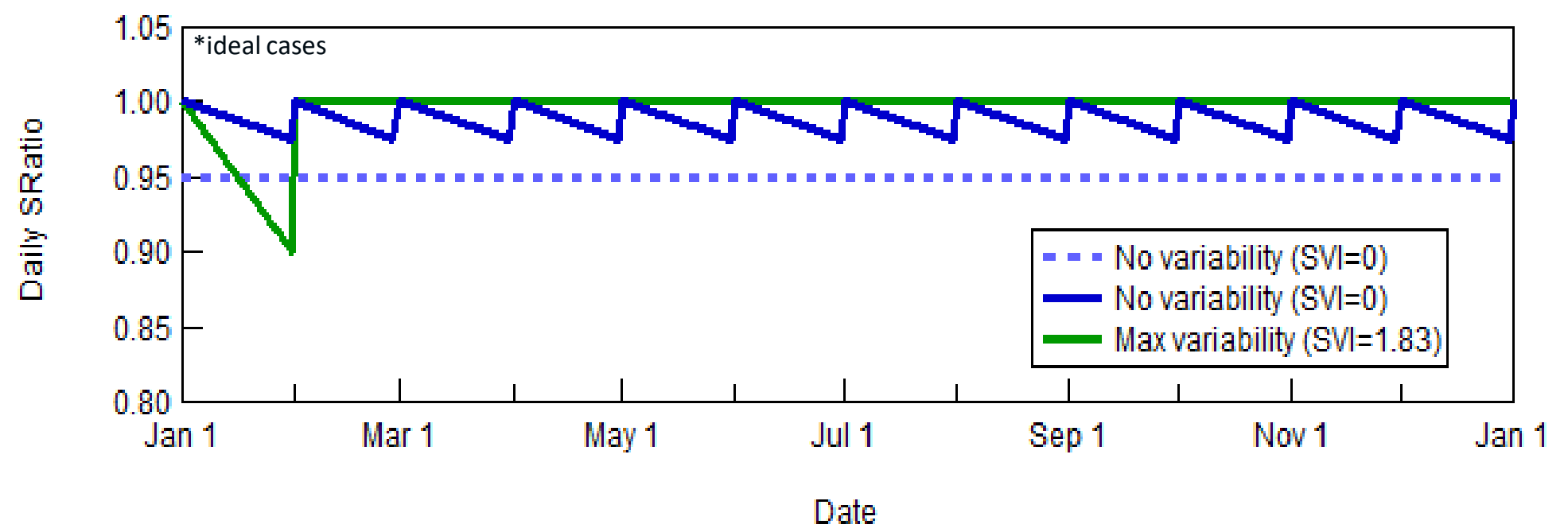

- No correction has been made to balance the different number of days among the various months. 


\section{Soiling Variability Index: Results}

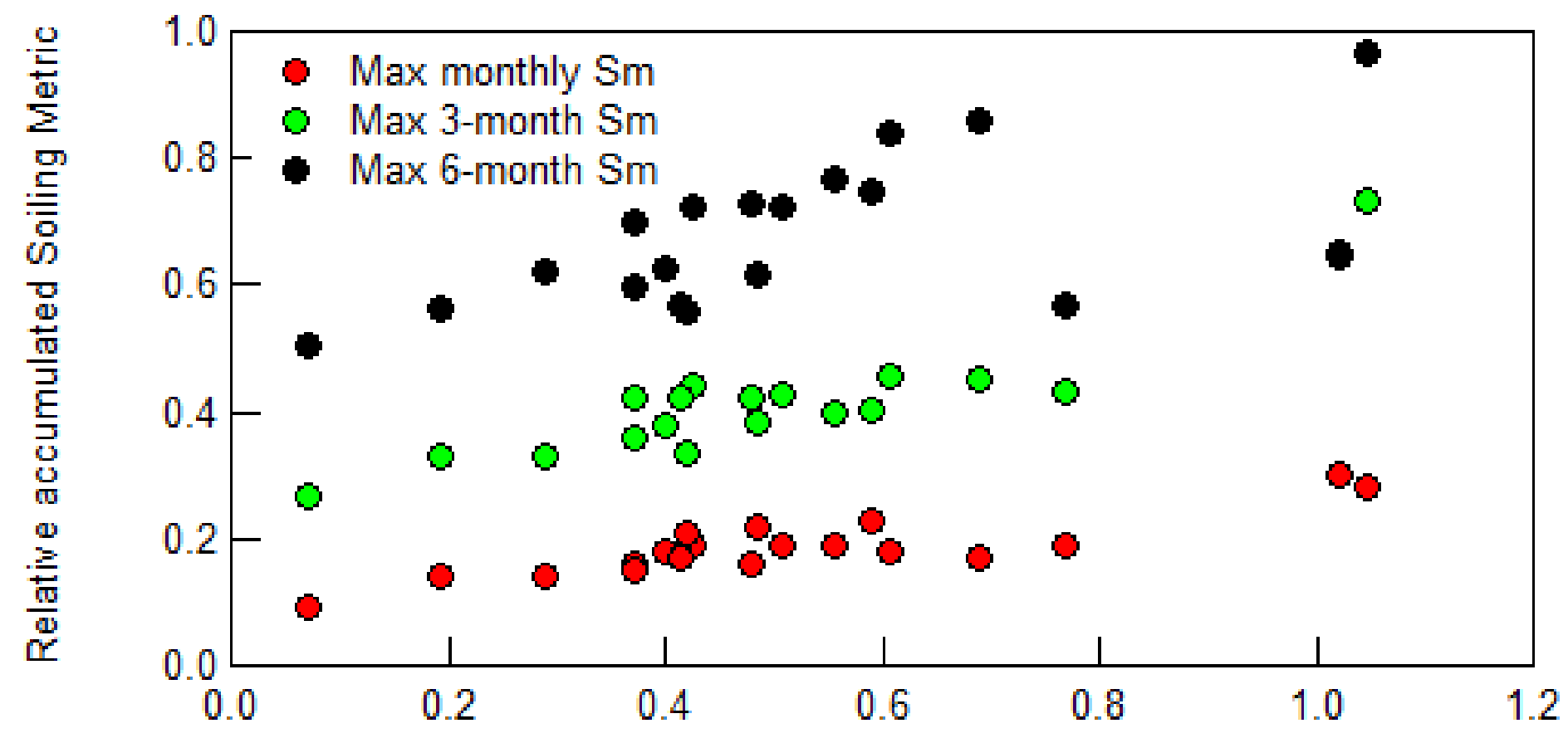

Soiling Variability Index

\begin{tabular}{|c|c|c|}
\hline Parameter & Description & $\mathbf{R}^{\mathbf{2}}$ (\%) \\
\hline Max monthly $S_{m}$ & Max $S_{m}$ registered in one month & 73 \\
\hline Max 3-month $S_{m}$ & Max $S_{m}$ when three consecutive months are considered & 82 \\
\hline Max 6-month $S_{m}$ & Max $S_{m}$ when six consecutive months are considered & 37 \\
\hline
\end{tabular}

SVI can be used to determine high soiling seasons occurring within a 12-month period. 


\section{Soiling Variability Index : Classification}

\section{The analyzed datasets fall into five categories:}

\begin{tabular}{|c|c|c|}
\hline SVI & Class & Soiling profile \\
\hline$<0.2$ & $\begin{array}{c}\text { Seasonal variability in soiling not } \\
\text { present or negligible. }\end{array}$ & $\begin{array}{c}\text { Losses are equally distributed during the year: } \\
\text { about } 50 \% \text { of the losses recorded in } 6 \text { months. }\end{array}$ \\
\hline$\geq 0.2$ and $<0.4$ & Limited seasonal soiling. & $\begin{array}{c}0 \% \text { to } 70 \% \text { of their soiling losses } \\
\text { occurring in } 6 \text { months. }\end{array}$ \\
\hline$\geq 0.4$ and $<0.6$ & $\begin{array}{c}\text { Non-negligible impact of seasonal } \\
\text { soiling. }\end{array}$ & $70 \%$ to $80 \%$ of the total losses occur in 6 months. \\
\hline$\geq 0.6$ and $<0.8$ & High variability in soiling. & $\begin{array}{c}\text { Most of the losses occur in } 3 \text { to } 4 \text { months and } \\
85 \% \text { to } 90 \% \text { of soiling is experienced in } 6 \text { months. }\end{array}$ \\
\hline$\geq 1.0$ & Extreme variability. & Almost all the losses (>95\%) occur in 6 months. \\
\hline
\end{tabular}




\section{Soiling Variability Index vs. Soiling Ratio}

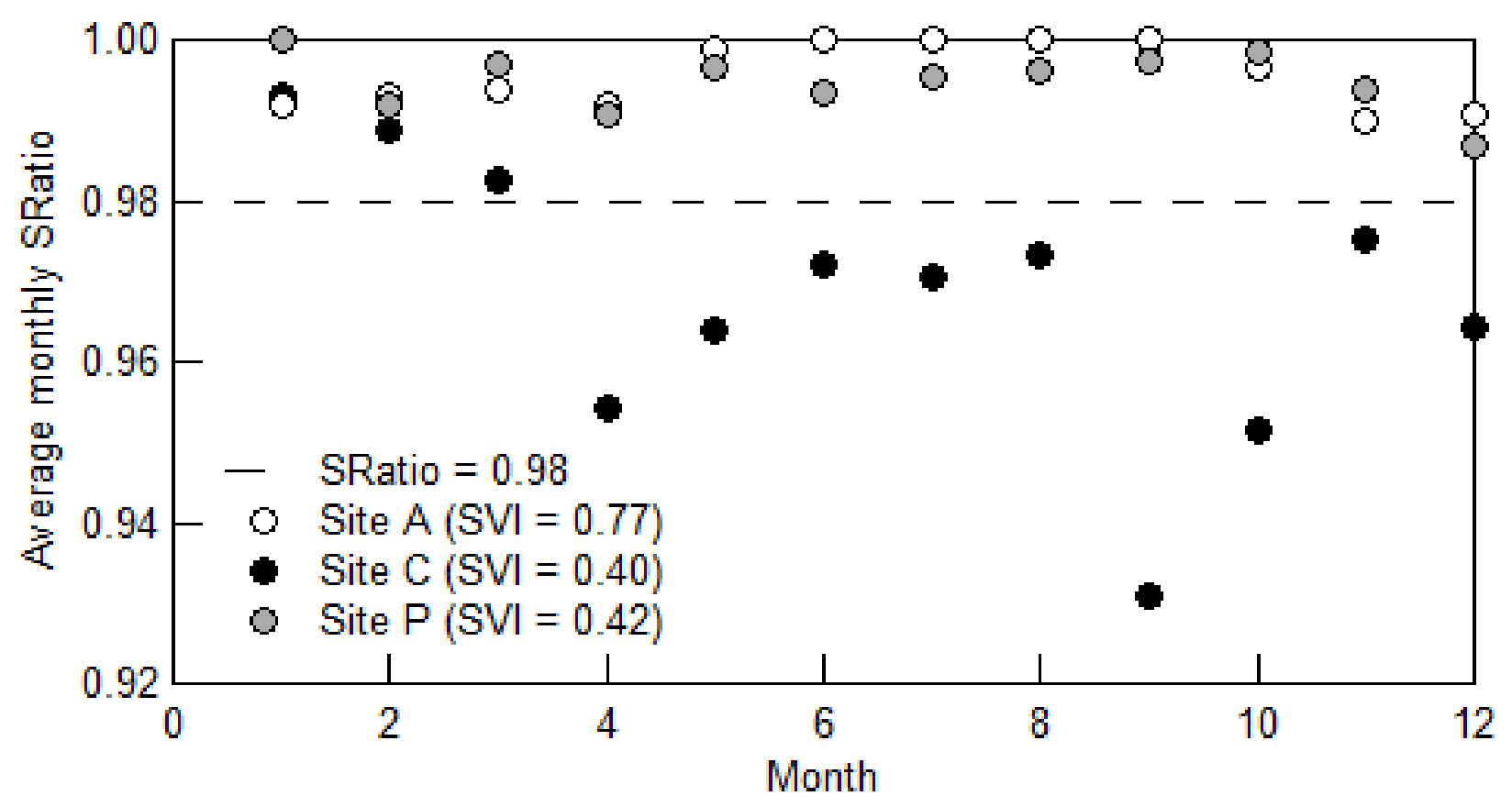

Site A: SRatio >0.99, SVI $=0.77$

Site C: SRatio $=0.97$, SVI $=0.40$.

Site P: SRatio $=0.99$, SVI $=0.42$.

Both the SVI and the annualized SRatio must be considered. 


\title{
Causes of seasonal soiling: Motivation
}

\section{Seasonality is generally determined using multi-year datasets.}

\begin{abstract}
Lacking such long soiling datasets, the prediction of seasonal soiling relies on identifying its correlation with other more widely available parameters.
\end{abstract}

The investigation here is limited to $\mathbf{P M}_{10}$ data. 


\section{Causes of seasonal soiling: Particulate Matter}

- $\mathrm{R}^{2}$ of $\mathbf{0 . 3 9}$ if the monthly accumulated daily losses compared against the accumulated daily $\mathrm{PM}_{10}$ concentrations.

- $\mathbf{R}^{2}$ of $\mathbf{0 . 4 7}$ if monthly data are replaced with data accumulated in three consecutive months.

- $R^{2}$ of 0.63 if data occurring for dry periods longer than 90 days are removed.
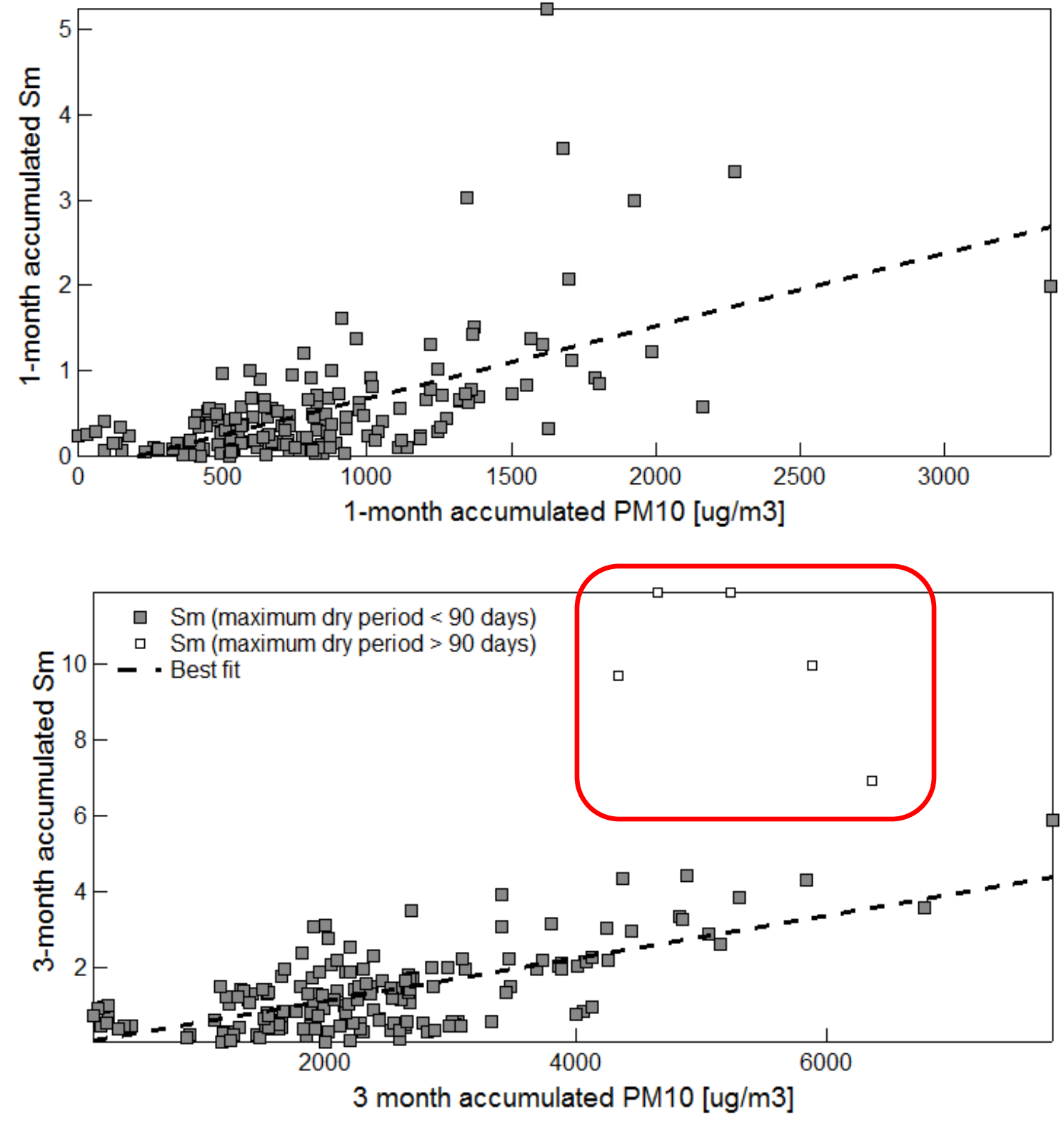


\section{Causes of seasonal soiling: Particulate Matter}

Lower $\mathbf{R}^{2}$ between SRatio and $\mathbf{P M}_{10}$ compared to our previous study:

- the variability of other parameters (e.g. rainfall) is more relevant for short than for longer time periods $[4,5]$.

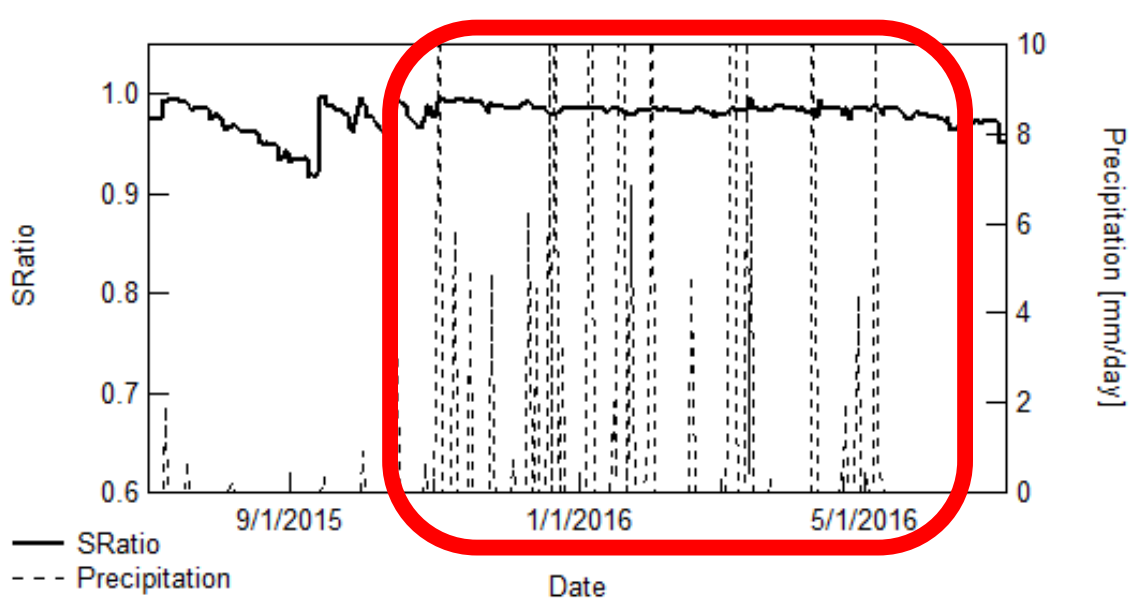

- daily PM10 registered by the EPA monitoring stations are discontinue and require an appropriate data process.

- the EPA monitoring stations might not be able, in some cases, to register the local seasonal PM10 trend of a site. 


\section{Causes of seasonal soiling: Particulate Matter}

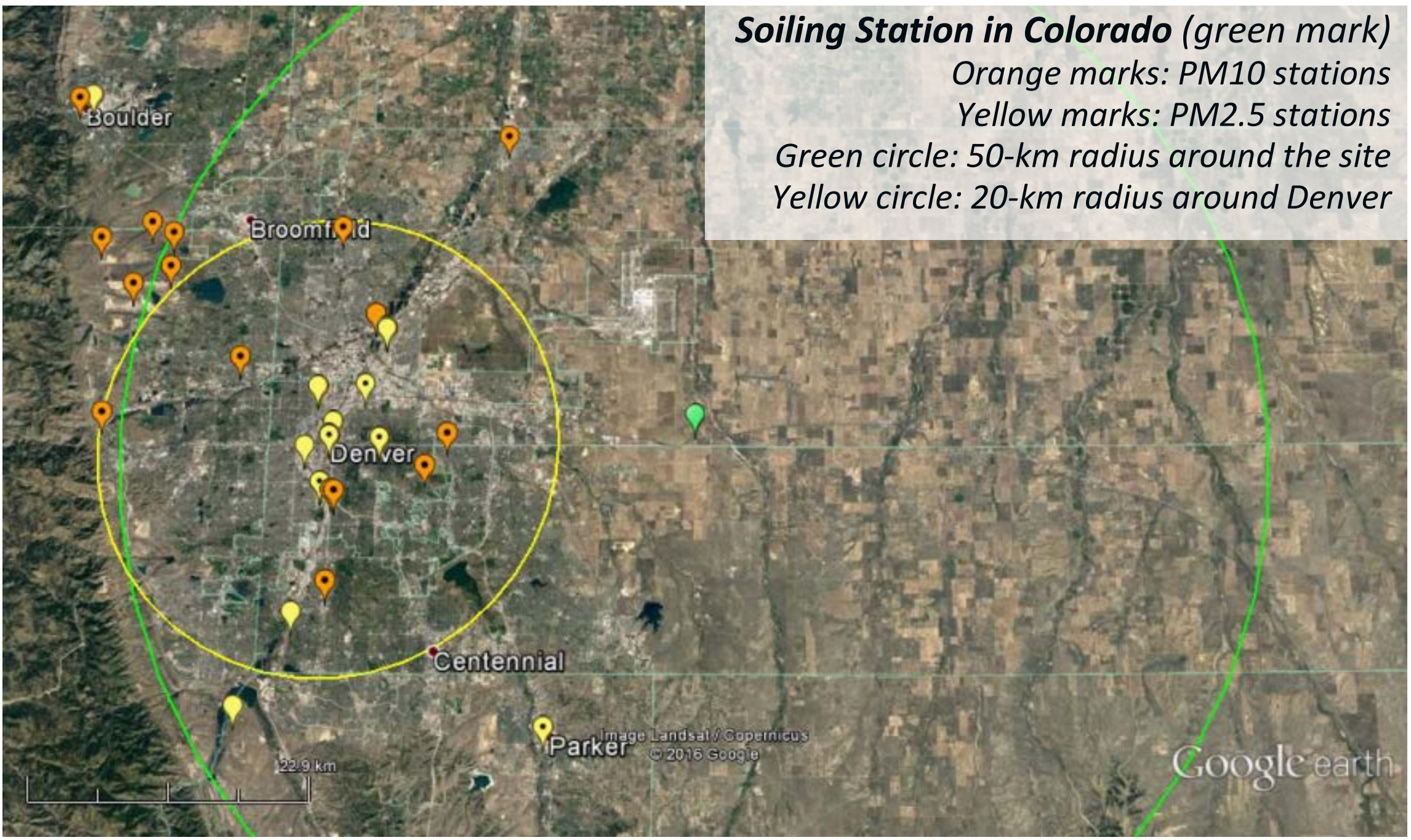

Source: 39.75685 \& -104.62025. Google Earth, 12/30/16. 01/19/17. 


\section{Conclusions}

Initial results of an investigation on seasonal PV soiling, using data from 15 stations in the USA.

- Seasonal variability index (SVI) introduced to quantify the seasonal behavior of soiling over a 12-month period.

- SVI used to classify the sites depending on the number of months in which most of the soiling losses occurred.

- SVI cannot distinguish high or low soiling sites.

- Correlations among monthly soiling and pollution data have lower accuracy that those reported for longer-term data. Results enhanced if three month periods are considered. 


\section{Thank you!}

\section{Leonardo Micheli Leonardo.Micheli@NREL.gov}

More on NREL soiling project on the thursday 10.30-12.00 Poster Session: Lin Simpson, NREL Efforts to Address Soiling on PV Modules (e-poster) Micheal Deceglie, Quantifying Year-to-Year Variations in Solar Panel Soiling from PV Energy-Production Data (K39)

Leonardo Micheli, A Unified Global Investigation on the Spectral Effects of Soiling Losses of PV Glass Substrates: Preliminary Results (K52)

Matthew Muller, A Method to Extract Soiling Loss Data From Soiling Stations with Imperfect Cleaning Schedules (L4)

\section{www.nrel.gov}

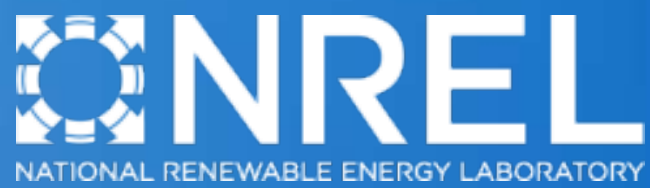




\section{Monte Carlo computation:}

the uncertainty can be particularly significant for low soiling ratio sites.

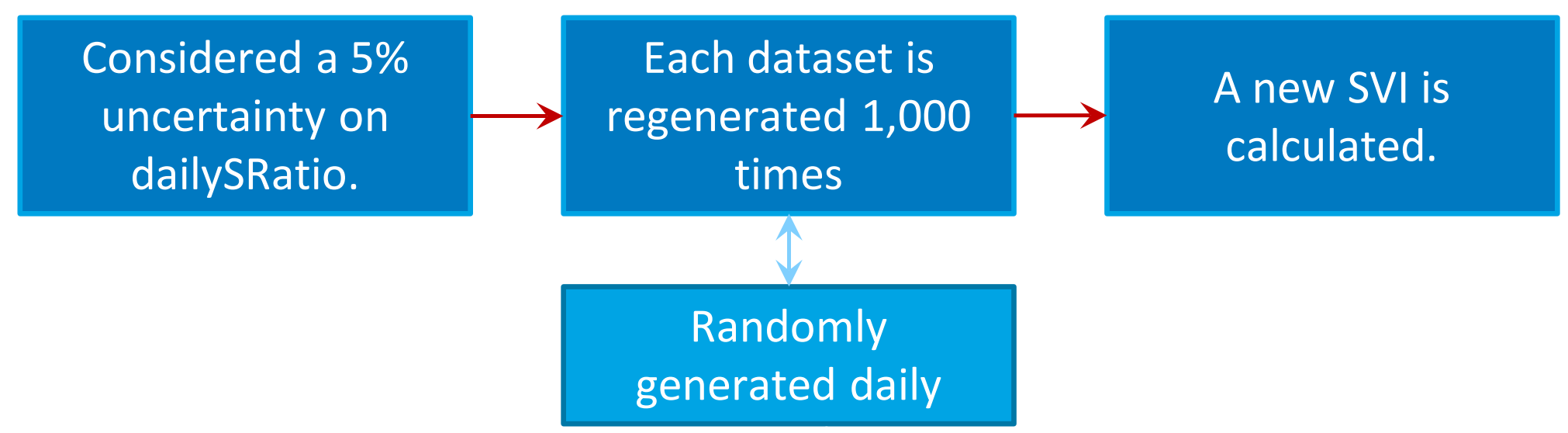

The uncertainty on SVI tends to increase with the soiling ratios, ranging from values of $1 \%$ to $42 \%$. 


\section{Introduction: Motivation}

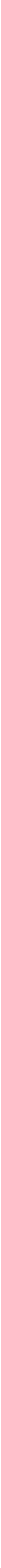

